\title{
O lado sombrio do termo "MADRASTA": O funcionamento da memória discursiva
}

The dark side of the term "STEPMOTHER": The functioning of the discursive memory

\author{
Stefania Ariadna Gomes ${ }^{1}$ \\ Recebido em: 24/05/2019
}

Aprovado em: 24/06/2019

Publicado em: 30/07/2019

RESUMO: Este artigo tem como objetivo analisar os sentidos do termo "madrasta", a fim de descrever o funcionamento da memória discursiva sobre essa figura, que está presente não somente nos contos de fadas, mas também exerce um papel na sociedade. Para tanto, o corpus de análise é constituído de três contos de fadas, cinco reportagens e um manual de instruções para a "boadrasta". Assim, buscamos, a partir do referencial teórico da Análise do Discurso, desenvolver uma análise da representação das madrastas que são vilãs nesses contos e mostrar que essa representação não aparece somente em contos de fadas, já que esse lado macabro também funciona textos jornalísticos.

Palavras-chave: Análise do Discurso; Memória discursiva; Contos de Fada; Formação de palavra.

ABSTRACT: This article aims to analyze the meanings of the term "stepmother" in order to describe the functioning of discursive memory about this figure that is present not only in fairy tales, but also plays a role in society. Therefore, the corpus of analysis consists of three fairy tales, five reports and an instruction manual for the "boadrasta". Thus, we seek, from the theoretical framework of Discourse Analysis, to develop an analysis of the representation of the stepmothers who are villains in these stories and to show that this representation does not only appear in fairy tales, since this macabre side also works in journalistic texts.

Keywords: Discourse Analysis; Discoursive memory; Fairy Tales; Word formation.

1. Graduada em Letras Português e Inglês pela Universidade Federal do Triângulo Mineiro.ORCID: 00000002-1628-3573 E-mail: s.t182@hotmail.com

2. Licenciada em Letras. Doutora em Linguística. Mestra em Linguística. Professora voluntária no Departamento de Linguística e Língua Portuguesa da Universidade Federal do Triângulo Mineiro.ORCID: 0000-0002-9267-1682 E-mail: daiane.unicamp@gmail.com 


\section{INTRODUÇÃO}

O termo "madrasta" tem circulado de forma marcada negativamente como sinônimo de perversidade e de maldade, como se houvesse no próprio termo algo que justificasse essa associação. ${ }^{1}$ Segundo o dicionário Priberam, o termo "madrasta" vem do latim "mater" e significa "esposa ou companheira do pai [...] em relação aos filhos por ele tidos em relacionamento anterior". ${ }^{2}$ Além dessa acepção, o dicionário atesta mais duas classificadas como depreciativas: "mãe que não cuida bem dos filhos" e "mulher má". O dicionário Michaelis também apresenta uma definição mais neutra de madrasta como "mulher casada em relação aos filhos que seu marido teve de casamentos anteriores". ${ }^{3} \mathrm{E}$ uma acepção em sentido depreciativo: "mulher má, incapaz de revelar gestos de ternura", que atesta o caráter pejorativo do termo. Além disso, esse dicionário ainda afirma que o termo pode funcionar como adjetivo, tendo o sentido de algo que "não oferece benefícios, apenas dissabores e tristezas", como, por exemplo, na expressão "vida madrasta", que funciona como sinônimo para vida ruim. Desse modo, apesar de seu sentido mais neutro, o termo tem circulado fortemente em seu sentido depreciativo.

Em contraposição, surgiu na língua portuguesa uma variação dessa palavra: o termo "boadrasta", que visa a apagar o sentido marcado negativamente do termo "madrasta". A respeito do processo de formação de palavras, de acordo com Cardoso (2010), uma das capacidades mais criativas do ser humano é o poder de criação de novas palavras a partir de outras já existentes, não como forma de representar algo novo, mas de forma estilística, de modo a expressar uma forma inédita de algo já existente. $\mathrm{O}$ autor explica que a chamada criatividade não seria o único fator para a criação de palavras, a história também aparece como uma das condicionantes dos novos termos, conforme propõe Guilbert (1981, p. 77-78 apud CARDOSO, 2010, p. 215).

A criação lexical deve ser situada, por um lado, numa determinada época, em virtude de sua pertinência à história do léxico, ligada à história da sociedade, e por outro, vista em função da individualização das criações feitas por locutores identificados na comunidade linguística.

\footnotetext{
1 Um exemplo dessa associação aparece na reportagem, intitulada "Madrasta, uma palavra que já nasceu torta", publicada pelo site da revista Veja em 16 de fevereiro de 2017. Disponível em: <https://veja.abril.com.br/blog/sobre-palavras/madrasta-uma-palavra-que-ja-nasceu-torta/>. Acesso em 09 nov. 2018.

2"Madrasta" in Dicionário Priberam da Língua Portuguesa. Disponível em: <https://dicionario.priberam.org/madrasta> Acesso em: 10 out. 2018.

3"Madrasta" in Dicionário Michaelis. Disponível em: <https://michaelis.uol.com.br/modernoportugues/busca/portugues-brasileiro/madrasta/> Acesso em:10 out. 2018.
} 
GOMES, S.A.; BITENCOURT, D.R.O.

Cardoso (2010) explica que a palavra "madrasta" ganhou, a partir da sua circulação nos contos de fadas, um sentido diferente do que originalmente tinha em seu uso dicionarizado: essa palavra, ao passar pelos contos de fadas, popularizados pelos irmãos Grimm, ganhou um sentido negativo, sendo que a primeira sílaba da palavra tem sido interpretada como um prefixo, que representa a forma "má", aquilo que é oposto a "boa". Assim, o termo madrasta seria interpretado como a junção do prefixo "má" (de malvada) ao radical "drasta".

De acordo com o autor, a partir dessa divisão da palavra foi possível substituir o sentido negativo pela palavra "boa", levando em consideração que nem todas as madrastas são más, o que resultou no termo "boadrasta". Entretanto, o autor ressalta que a palavra madrasta não é, na verdade, o cruzamento de duas palavras, mas há, na formação de "boadrasta", um aproveitamento do suposto significado (primeira sílaba), substituído por outro, sendo considerado um cruzamento ou mesclagem lexical, "em que pelo menos duas palavras se unem" (CARDOSO, 2010, p. 218), produzindo uma nova palavra com um significado cultural.

Minussi e Nóbrega (2014) também analisam o termo "boadrasta" a partir da relação sintaxe-pragmática na formação das palavras. Os autores abordam os diferentes processos de formação de palavras, levando em consideração o conhecimento enciclopédico ${ }^{4}$, tanto das raízes das palavras quanto de objetos construídos sintaticamente. Defendem que há três tipos de blends ${ }^{5}$ na formação das palavras no âmbito falado da língua: o fonológico, o morfológico e o semântico. O blend fonológico acontece em casos como em "chafé" em que há a fusão da palavra chá + café, sendo que a primeira sílaba, "chá", tem o som parecido com a parte que foi oculta da palavra café. O blend morfológico diz respeito às palavras que sofrem "diminuição do corpo fônico", além de ser formado "por dois elementos com conteúdo semântico" e "permitem as mesmas relações gramaticais expressas nos compostos, por exemplo: subordinação, atribuição e coordenação" (MINUSSI; NOBREGA, 2014, p.165), formando palavras como "bebemorar", da palavra "comemorar", que relaciona comer + festejar. Porém, hoje em dia, como explicam os autores, as pessoas preferem beber ao invés de comer, gerando a palavra formada por "beber" + "comemorar" = "bebemorar". Por fim, a terceira combinação seria a formação de blends semânticos, "em que há uma análise semântica de um

\footnotetext{
4Segundo Koch e Elias (2015), existem três grandes sistemas de conhecimento para o processamento textual. São eles:o linguístico, o enciclopédico e o interacional. $O$ enciclopédico diz respeito a conhecimentos gerais de mundo que o sujeito possui armazenado na memória, permitindo a produção de sentidos. Um exemplo seria saber o modo como o sujeito deve se comportar na sociedade.

${ }^{5}$ Processo morfológico em que há a fusão estrutural de duas palavras fontes.
} 
conjunto de segmentos fonológicos de uma das palavras fontes" (MINUSSI; NOBREGA, 2014, p.162); como é o caso da palavra "madrasta" que se torna "boadrasta", por um "input enciclopédico", isto é, "informações concernentes ao nosso conhecimento de mundo" (MINUSSI; NOBREGA, 2014, p.171), que desencadeiam "a sobreposição ou apagamento de segmentos fonológicos" (MINUSSI; NOBREGA, 2014, p.163). O blend é formado por duas palavras fontes, em que "boadrasta" é analisado de forma a substituir seu segmento fonológico de uma das palavras-fontes por um segmento semântico diferente e com traços enciclopédicos distintos, gerando assim, um efeito de significado contrário ao que era considerado culturalmente.

Dessa forma, os autores concluem que, ao eliminar a raiz "ma" de madrasta, que culturalmente é possuidora de traços como <defeito>, <incorreto>, <não virtude>, esse significado é apagado, "e os segmentos restantes são fundidos com os segmentos da raiz "boa", a qual já sofreu inserção de vocabulário e é detentora de traços enciclopédicos opostos" (MINUSSI; NOBREGA, 2014, p. 178).

Sendo assim, segundo essas teorias, ao deparar-se com o termo "boadrasta", o leitor o interpreta como aquela que gosta dos filhos do marido; que é uma boa pessoa; que assume papel de mãe etc. Entretanto, considerando a circulação dos sentidos, a partir do referencial teórico da Análise do Discurso, propomos que esta nova forma linguística não apaga a memória negativa em relação ao termo, ligada aos contos de fadas, em que a maioria das histórias tem uma madrasta má.

Tendo isso em vista, o objetivo artigo é investigar a circulação e o funcionamento dos termos "madrastra" e "boadrasta" em diferentes gêneros discursivos, a fim de analisar como se constrói uma memória discursiva sobre essa figura. Para tanto, a análise será feita a partir dos pressupostos da Análise do Discurso de linha francesa, mais especificamente, da noção de memória discursiva de Courtine (1999).

Este artigo organiza-se do seguinte modo: apresentamos, primeiramente, a fundamentação teórica e a metodologia utilizada. Em seguida, traçamos um percurso sobre a história das madrastas. A seguir, analisamos três contos de fadas, a saber, Os seis cisnes, Branca de Neve e Cinderela, na versão dos irmãos Grimm (2018). Analisamos também excertos de cinco reportagens que tratam de madrastas, a fim de discutir como os sentidos desse termo aparecem em funcionamento. Por fim, realizamos a análise do guia "Dez mentiras que as boadrastas contam", com o intuito de discutir a circulação desse novo termo na língua e apresentamos as conclusões desta pesquisa. 


\section{A memória discursiva}

Jean-Jaques Courtine (1999) propõe o conceito de "memória discursiva" na perspectiva da Análise do Discurso. Para esse campo de conhecimento, a memória não corresponde à memória cognitiva/psicológica dos falantes, pois não é da ordem da língua, mas do discurso. $O$ autor enfatiza a diferença entre essas duas ordens: a ordem do discurso "constitui o sujeito falante (da ordem da língua) em sujeito de seu discurso" (COURTINE, 1999, p. 16). Assim, para ser sujeito do discurso, é preciso se assujeitar à ordem do discurso, uma vez que só enunciamos no interior de um dado discurso. Essa questão do assujeitamento é, portanto, uma condição obrigatória. É essa interpelação que vai explicar o aparecimento do sujeito no interior do discurso: não é o sujeito falante que cria o discurso, uma vez que os sentidos desse discurso não são controlados por esse sujeito, pois o discurso tem uma ordem que lhe é própria e uma memória, em que o sujeito vai retomar enunciados, dizendo coisas que qualquer sujeito falante que se inscreve no mesmo discurso diria, isto é, o que o discurso autoriza/permite dizer.

Courtine (1999) defende que a memória discursiva está ligada aos discursos, àquilo que os sujeitos que aderem a um determinado discurso podem/devem se lembrar e àquilo que um discurso silencia. Para o autor, no funcionamento da memória, há tanto um silenciamento quanto uma saturação, isto é, a necessidade de que certos acontecimentos sejam sempre lembrados e de que certas coisas sejam sempre repetidas. Nesse sentido, no domínio da memória, é sempre ou o muito ou o apagamento.

Para propor o conceito de memória discursiva, Courtine (1999) apresenta a história de um dirigente comunista, Gottwald, que aparece em uma sacada cercado por seus "camaradas", próximo a ele está Clémentis, que pelo tempo frio, retira seu chapéu e coloca na cabeça de Gottwald. O departamento de propaganda faz uma foto do líder com o chapéu de Clémentis e reproduz milhares de exemplares desta fotografia. Quatro anos depois, Clémentis foi acusado de traição e, por conseguinte, foi enforcado e apagado da foto, restando dele apenas o chapéu na cabeça de Gottwald. A partir desse acontecimento, Courtine (1999) interroga qual é o papel da memória no discurso político, já que não é uma materialidade linguística, mas um o apagamento não-linguístico. "É antes de tudo, na ordem do discurso que ele é produzido" (COURTINE, 1999, p. 16), ou seja, como constituinte do próprio discurso, já que todo discurso tem uma memória discursiva que remete aos enunciados que são retomados, aos enunciados que possibilitam a ligação com outros. Assim, esses enunciados fazem parte dessa memória e 
servem de base para a construção, para a enunciação de outros enunciados. $\mathrm{O}$ autor acrescenta que $a$,

ordem do discurso das "línguas de estado", que dividem em pedaços a lembrança dos eventos históricos, preenchidos na memória coletiva de certos enunciados, dos quais elas organizam a recorrência, enquanto consagram a outros a anulação ou a queda (COURTINE, 1999, p.16).

Courtine (1999) faz uma divisão em que os enunciados são organizados em um eixo horizontal e em um eixo vertical, sendo o horizontal a superfície das formulações. Por exemplo, "os comunistas são traiçoeiros" é um enunciado do discurso cristão. Já o eixo vertical vai organizar, por exemplo, "são traiçoeiros; são mentirosos; são perigosos", sendo todos esses enunciados que constituem a memória desse discurso cristão, ou seja, é o que se pode dizer na ordem do discurso cristão/ católico. Em seguida, o autor discute os mecanismos para a retomada desses enunciados que constituem essa memória, denominado "domínio da memória, que constitui a exterioridade do enunciável para o sujeito enunciador na formação dos enunciados 'pré-construídos', de que sua enunciação apropria-se" (COURTINE, 1999, p.18). A memória, como proposta pelo autor, é, portanto, uma coerção, porque existem enunciados que podem ser ditos e existem enunciados que não figuram nesse domínio, ou seja, não fazem parte do dizer de determinado discurso. Esses enunciados constituem o domínio da memória de um dado discurso. Sendo assim, as formulações que vão reaparecer com mudanças, com transformações, mas sempre repetindo o que pode ser enunciável nesse discurso.

Em Papel da memória, Michel Pêcheux (2010) também aborda o funcionamento da memória, discutindo as condições nas quais um acontecimento histórico pode inscreverse em uma memória discursiva. Pêcheux cita as postulações de Achard, o qual defende que a memória absorve as informações e, ao mesmo tempo, pode desmanchá-las e produzir efeitos novos em relação às primeiras informações, ou seja, "o acontecimento, no caso, desloca e desregula os implícitos associados ao sistema de regularização anterior" (PÊCHEUX, 2010, p.52). O autor considera esse efeito como "um jogo de força na memória, sob o choque do acontecimento":

- um jogo de força que visa manter uma regularização pré-existente com os implícitos que ela veicula, confortá-la como "boa forma", estabilização parafrástica negociando a integração do acontecimento, até absolvê-lo e eventualmente dissolvê-lo.

- mas também, ao contrário, o jogo de força de uma "desregulação" que vem perturbar a rede dos "implícitos". (PÊCHEUX, 2010, p. 53). 
GOMES, S.A.; BITENCOURT, D.R.O.

Sendo assim, pensando na inscrição de novos acontecimentos que desregulam a memória, seria esperado que, com a criação do novo termo "boadrasta", a memória negativa desaparecesse.

\section{METODOLOGIA}

Para análise, foram selecionados primeiramente três contos dos Irmãos Grimm publicados em 2018 pela editora Nova Fronteira no Rio de Janeiro. Os contos selecionados foram Branca de Neve, Cinderela e Os Seis Cisnes. A seguir, foi realizada uma busca no Google pelo termo "madrasta", a qual resultou em basicamente dois tipos de respostas: ou "receitas" de como ser uma boa madrasta, ou reportagens que tratam da participação de madrastas em crimes. Sendo assim, selecionamos para análise alguns trechos de cinco reportagens e uma dessas "receitas" de como ser uma boa madrasta, a saber, um manual de instruções intitulado "As dez mentiras que as boadrastas contam".

\section{ANÁLISES}

\section{A historicidade da representação da madrasta}

Em 2016, a revista Super Interessante publicou, pela editora Abril, um livro intitulado "O lado sombrio dos contos de fadas" de autoria de Karin Hueck, em que alguns contos são analisados de acordo com sua origem, antes de serem transformados pela Walt Disney em animações para crianças.

O capítulo "A bela adormecida, as sogras e as madrastas más" mostra como essas figuras eram bem piores do que as das versões cinematográficas de hoje em dia. A fim de explicar essa terrível fama, a autora volta cerca de 4 milhões de anos, quando os primatas, nossos antepassados, habitavam as florestas da África e, por motivos explicados pela biologia e geografia, passaram a se equilibrar sobre duas patas, dando origem aos hominídeos que resultaram em nós, Homo sapiens. Segundo a autora, ser bípede foi essencial para nos tornarmos a espécie que dominaria o planeta, fazendo alterações anatômicas, principalmente no nosso quadril, que se estreitou. Essa redução de tamanho gerou um problema em relação ao parto, na hora da passagem do bebê pelo canal vaginal, já que nossa cabeça também aumentou por termos cérebros mais avantajados e evoluídos em relação aos outros animais. Juntando cabeça maior com 
quadril menor, surge, então, um problema para as mães, que os cientistas chamam de "dilema obstétrico".

Desse modo, dar à luz virou uma situação de risco para a mulher, fazendo com que muitas não sobrevivessem ao nascimento do filho, gerando uma taxa de mortalidade bem mais alta do que hoje em dia. Geoffrey Chamlerlain, da Universidade de Wales, afirma que ocorria a morte de mulheres mais jovens, que deixavam o filho com o marido viúvo. Nem sempre, as mulheres morriam na primeira gravidez, deixando para trás, às vezes, vários filhos, que eram criados pelos pais que, por não darem conta de sustentar os filhos sozinhos, casavam-se novamente. Dessa forma, as novas esposas entravam na família tendo que cuidar dos filhos deixados pela mulher, o que explica o surgimento de tantas madrastas.

Além disso, segundo Hueck (2016), naqueles tempos, com a pobreza, é de se imaginar que as esposas tratassem melhor os seus filhos biológicos, como uma lógica de sobrevivência. De acordo com Coontz (2005), um caso extremo, por exemplo, aconteceu no século $X$ com os filhos de Edgar, um rei anglo-saxão, que casou pela segunda vez para ter ainda mais herdeiros. Quando esse rei morreu, houve uma grande disputa pelo trono, a qual foi vencida pelo primogênito do primeiro casamento. Quatro anos depois o novo rei foi fazer uma visita à madrasta que o recebeu com uma taça de vinho, e enquanto o garoto bebia, um servo da corte o esfaqueou, tomando posse do reino, assim, o filho da viúva.

Hueck (2016) afirma que algumas dessas histórias de madrastas foram inventadas pelos irmãos Grimm, quando escreviam seus contos para crianças. De acordo com pesquisadores, é importante apresentar esses contos aos filhos, para que comecem a entender essa "troca" da mãe pela nova esposa do pai. A autora explica que, para os psicanalistas:

Do ponto de vista dos filhos, as mães da vida real cumprem dos dois papéis: o de progenitora bondosa e o de madrasta má, em diferentes situações da vida e em cada fase do desenvolvimento da criança. Ou seja, a ocorrência de tantas madrastas seria apenas uma metáfora para a maneira como o filho vê a mãe em situações de tristeza, raiva ou amadurecimento (HUECK, 2016, p. 120).

Falcke e Wagner (2000) analisam os mitos sociais entre os papéis de mãe e madrasta, a partir de uma entrevista com 50 mães e 50 madrastas. As autoras apontam que as mães e as madrastas afirmam que é fácil encontrar "exemplos na vida real que mostrem como é uma boa madrasta", sendo que as madrastas são as que mais acreditam nisso. Destarte, podemos considerar que as madrastas não se consideram más. 
GOMES, S.A.; BITENCOURT, D.R.O.

Por outro lado, as autoras afirmam que, levando em consideração o resultado da pesquisa, "parece que é mais difícil para mães que para madrastas aceitar a possibilidade de que outra pessoa exerça de forma satisfatória a função materna" (FALCKE; WAGNER, 2000, p. 431), o que leva a madrasta atuar em posição de concorrência com a mãe já que gostaria de ter o mesmo papel que ela. Levando em consideração a frase "mãe é uma só", $66 \%$ das mulheres entrevistas pelas autoras afirmam a veracidade da frase, mostrando assim que a mãe é vista como uma figura insubstituível. Analisando essa relação, Falcke e Wagner (2000) definem que, para Badinter (1985), há um mito do amor materno, uma vez que se acredita que "o fato de ser mãe, por si só, desperta na mulher uma predisposição inata para amar seu filho de forma incondicional" (FALCKE; WAGNER, 2000, p. 430), tornando-a, desse modo, insubstituível. Há, portanto, uma relação tensa entre essas duas figuras.

Um exemplo dessa relação também é encontrado no provérbio popular "amor só de mãe", em que o sentimento é atribuído somente à mãe de um modo restritivo pelo uso do operador argumentativo "só". Essa exaltação da mãe cria opostamente uma restrição a respeito da madrasta, já que o seu amor não pode ser o mais verdadeiro, ela apenas "faz papel de mãe". Outro provérbio sobre o tema é "Madrasta, o nome the basta", o qual foi analisado por Silva (2014). Segundo a autora, nesse provérbio, a carga semântica do substantivo se torna completa pelo termo "basta", dado que o termo madrasta já carregaria todos os significados que indicam repulsa, seja tanto pelo contexto cultural quanto pela própria estrutura da palavra "ma+drasta", sendo "ma" considerado como um adjetivo que causa rejeição proveniente dos contos de fadas que ficaram internalizados em nossa cultura, relação que já foi discutida neste artigo. Após apresentar essa discussão, a autora defende que a "compreensão do sentido de um provérbio está atrelada ao conhecimento linguístico e cultural dos interlocutores que dele fazem uso" (SILVA, 2014, p. 18). Portanto, os provérbios retomam e põem em circulação saberes que circulam na sociedade. No caso do sema "mãe" nos provérbios, a autora conclui que este carrega valores positivos, enquanto o sema "madrasta" caminha,

em direção oposta ao comportamento atribuído à figura materna, uma vez que o intento é sustentar o mito de que nenhuma outra mulher, a não ser a mãe, pode cumprir a missão da maternidade ou exercer funções atribuídas a esse estatuto social (SILVA, 2014, p. 21).

Sendo assim, propomos neste artigo que a figura da madrasta funciona como um avesso à figura da mãe. Se, por um lado, a mãe é descrita como boa, abnegada, 
GOMES, S.A.; BITENCOURT, D.R.O.

carinhosa, retomando da tradição cristã/católica a figura da mãe "santa e imaculada"; a madrasta, por sua vez, é retratada como má, egoísta, invejosa.Tendo em vista a tensão entre essas duas imagens, analisamos a seguir a figura da madrasta nos contos de fadas.

\section{A figura da madrasta nos contos de fadas}

Considerando os pontos discutidos, selecionamos, para análise, três contos que representam a figura da madrasta. O primeiro conto escolhido é o da Branca de Neve, o qual narra a história de um rei que, após a morte de sua mulher, se casa com uma bela princesa, porém muito má e orgulhosa. A rainha tinha o costume de consultar seu espelho mágico, perguntando-Ihe se havia alguém mais bela em toda a redondeza, é surpreendida pela resposta do espelho de que lhe diz que a sua enteada, Branca de Neve, é a mais bela. Furiosa por haver alguém mais bela que ela em seu reino, a madrasta manda matar a filha do rei e, como prova do crime, pede ao caçador para trazer o fígado e o coração da jovem. Quando descobre que a garota ainda estava viva, faz de tudo para matar a garota envenenando-a com uma maçã, mas a garota volta a viver quando o ajudante do príncipe, que carregava o caixão para castelo, tropeça e a menina cospe o pedaço da maçã que estava em sua garganta. Cabe ressaltar que o final do conto que ficou na memória coletiva foi o da versão da Disney, em que o que salvou Branca de Neve foi o beijo do príncipe, sendo, assim, um final mais romantizado e não acidental como o proposto pelos irmãos Grimm.

Para análise do conto, selecionamos um conjunto de formulações que descrevem a madrasta:

(i) "Decorrido o ano do luto, o rei casou-se em segunda núpcias com uma princesa de grande beleza, mas extremamente má e orgulhosa" (GRIMM, 2018, p. 63, destaque nosso).

(ii) "A rainha estremeceu e ficou verde de inveja. E daí, então, cada vez que via Branca de Neve seu coração tinha verdadeiros sobressaltos de raiva. Sua inveja e seus ciúmes desenvolviam-se qual erva daninha, não Ihe dando mais sossego, nem de dia nem de noite" (GRIMM, 2018, p. 66, destaques nossos).

(iii) "A rainha ficou furiosa, pois sabia que o espelho não podia mentir. Percebeu, assim, que o caçador a enganara e que Branca de Neve continuava a viver. Novamente devorada pelo ciúme e pela inveja, só pensava numa maneira de fazer a menina desaparecer. " (GRIMM, 2018, p. 70, destaques nossos).

(iv) "A essas palavras, a rainha sentiu o sangue gelar nas suas veias. Empalideceu de inveja e, depois, torcendo-se de raiva, compreendeu que a rival ainda estava viva. Pensou novamente num meio de se livrar dela, causa de seu rancor. " (GRIMM, 2018, p. 72, destaques nossos) 
(v) '“Ah, desta vez hei de arranjar alguma coisa que será a tua ruína! 'E, como entendia de bruxarias, pegou um belo pente cravejado de pérolas e o mergulhou num veneno feito por ela própria" (GRIMM, 2018, p. 72, destaque nosso).

(vi) "A perversa mulher começou a gritar e ficou tão exasperada que não podia controlar-se e não queria mais ir à festa. Entretanto, como a inveja não lhe dava tréguas, sentiu curiosidade de ver a jovem rainha." (GRIMM, 2018, p. 78, destaques nossos).

(vii) "A horrível mulher fitava-a como uma serpente." (GRIMM, 2018, p. 78, destaques nossos).

Esse conjunto de formulações permite construir paráfrases como: a madrasta é má, invejosa, orgulhosa, rancorosa, ciumenta, raivosa, feiticeira, ou seja, uma bruxa. Em (vii), por exemplo, a comparação da madrasta com a serpente retoma o caráter venenoso da madrasta que prepara feitiços para Branca de Neve. Assim, análise das formulações permite apreender o funcionamento da memória, conforme explicitado por Courtine (1999), que retoma, no eixo vertical, pré-construídos da madrasta como uma pessoa má.

O segundo conto escolhido é o da Cinderela, que narra a história de um homem que após a morte da esposa, se casa novamente com uma mulher que já tinha duas filhas bonitas, "mas de coração cruel e feio" (GRIMM, 2018, p. 151). A mulher e suas filhas tratavam a filha do rei como uma escrava, obrigando-a a fazer tudo o que queriam, e, por viver sempre suja e cheia de cinzas, apelidaram-na de Cinderela. Certa vez, quando sua madrasta a privou de ir a um baile, Cinderela fez de tudo para conseguir ir e, no último dia de festa, perdeu seu sapato, o qual foi encontrado pelo príncipe que anunciou que se casaria com a dona do sapato. Neste conto, também podemos fazer uma menção à adaptação feita pela Disney, em que, quem ajuda Cinderela a ir ao baile é uma fada madrinha, enquanto na versão dos irmãos Grimm, a garota vai até o túmulo da mãe e sob uma árvore pede para que seja coberta de ouro e prata. No conto, quem realiza seu desejo é um pássaro que estava pousado na árvore.

Desse conto, selecionamos algumas passagens, por exemplo, quando a madrasta e suas filhas hostilizam Cinderela:

(viii) A segunda mulher trazia consigo duas filhas, bonitas, mas de coração cruel e feio. Começaram, então, dias bem tristes para a pobre enteada.

- Essa estúpida, palerma - diziam as recém-chegadas -, acha que vai ficar na sala conosco? Quem come o pão tem de ganhá-lo! Fora daqui, faxineira!

Tomaram-Ihe os belos vestidos, deram-Ihe uma roupa cinzenta para vestir e um par de tamancos.

- Vejam só! Vejam como está enfeitada a rica princesa! (GRIMM, 2018, p.151). 
GOMES, S.A.; BITENCOURT, D.R.O.

Assim, como é ilustrado nesse trecho, a madrasta e as filhas humilham Cinderela, são irônicas e mostram-se invejosas. No decorrer do conto, a madrasta engana Cinderela dizendo que ela poderá ir ao baile caso recolha as lentilhas da cinza. Entretanto, após realizar a tarefa duas vezes, a madrasta a humilha e não permite que vá ao baile, construindo uma imagem da madrasta como cruel e mentirosa.

Além disso, a análise do conto permite ver o modo diferente como a madrasta trata as filhas e a enteada. Enquanto as filhas têm conforto, Cinderela precisa servir toda a casa. Por exemplo, é Cinderela quem penteia o cabelo e engraxa os sapatos das irmãs. Dessa forma, no conto, estão em funcionamento duas imagens opostas: a da mãe protetora, que sempre trata as filhas bem, em contrapartida, a da madrasta má, que maltrata e abusa da enteada.

Por fim, no conto, ao saberem da sorte de Cinderela casar-se com o príncipe, a madrasta e as filhas ficam espantadas e com raiva, representando-as, mais uma vez, como invejosas e más. Os autores terminam o conto com a seguinte formulação: "assim foram punidas, com a cegueira, para o resto da vida, por terem sido tão falsas e perversas" (GRIMM, 2018, p. 161). Consequentemente, não apenas irmãs de Cinderela são punidas, mas a madrasta que tem que acompanhar o sofrimento das filhas.

O conto "Os Seis Cisnes", por sua vez, narram a história de um caçador que, ao perseguir sua caça, se perde na floresta e, ao tentar encontrar o caminho de volta para casa, se depara com uma bruxa. Ele lhe pede ajuda para encontrar a saída, mas ela propõe que só ensinará o caminho se ele se casar com a sua filha, tornando-a rainha. 0 rei aceita a proposta e se casa. Receando de que a madrasta não fosse tratar bem os seus filhos, ele decide levá-los a um castelo solitário no meio da floresta. Devido a sua frequente visita, a rainha começa a sentir a ausência do rei, então entra no meio da floresta para encontrar alguma pista, e ao encontrar todas aquelas crianças, joga um feitiço transformando-os em cisnes. Apresentamos alguns excertos do terceiro conto:

(ix) "Ela jogou uma blusa em cima de cada um deles e assim que elas lhes tocaram o corpo, eis que se transformaram todos em cisnes e voaram pela floresta". (GRIMM, 2018, p. 191).

(x) "A rainha voltou para casa muito satisfeita, julgando ter-se livrado dos enteados". (GRIMM, 2018, p. 191, destaque nosso).

(xi) "O rei ficou muito aflito, mas não desconfiou que tão cruel ação tivesse sido cometida pela rainha”. (GRIMM, 2018, p. 192, destaque nosso).

Desse modo, mais uma vez, nesse conto, aparece em funcionamento uma posição sobre a madrasta como bruxa, má, que trata mal os enteados. Ela tem ciúmes da atenção 
GOMES, S.A.; BITENCOURT, D.R.O.

que o marido dá aos filhos e, por isso, os enfeitiça. A seguir, passamos à análise do termo "madrasta" em reportagens da atualidade.

\section{Análise das reportagens: as madrastas atuais}

Ao pesquisar o termo "madrasta" no Google, a busca retoma várias de notícias publicadas em jornais e revistas online, que, em sua maioria, discutem crimes nos quais há a participação de madrastas. Selecionamos, para análise, trechos que se referem às madrastas como protagonistas ou ajudantes de crimes.

Tabela 1: Excertos de reportagens sobre as madrastas.

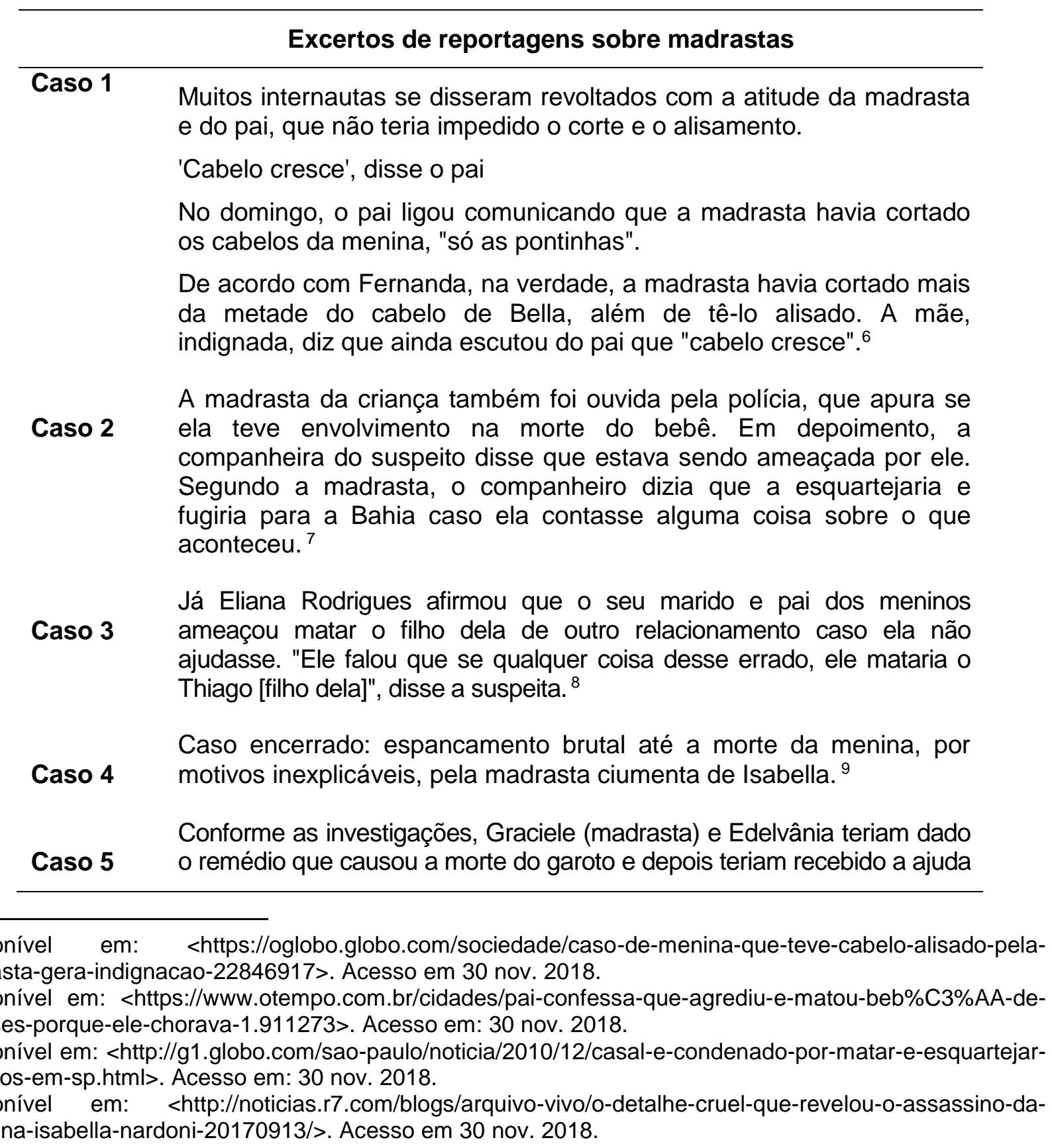


de Evandro para enterrar o corpo. O pai teria ajudado a planejar o crime, diz a polícia.

Nas imagens, ela aparece ao lado do advogado e diz que a criança morreu por causa do excesso de medicamentos dados pela madrasta.

$\mathrm{Na}$ época em que ocorreram as prisões, Edelvânia havia dito à polícia que a morte se deu por uma injeção letal e que, em seguida, ela e a amiga Graciele jogaram soda cáustica sobre o corpo. ${ }^{10}$

Fonte: Internet ${ }^{6-7-8-9 .}(2018)$.

Analisando os trechos apresentados na Tabela 1, podemos identificar a frieza por parte das madrastas em relação aos enteados a ponto de praticar ou ajudar em crimes contra eles. $O$ caso 1 é o da madrasta que alisou o cabelo da enteada. $O$ ato foi considerado, por internautas, como racismo e violação. A mãe da menina fez uma postagem em sua rede social, na qual desabafa sobre o ocorrido, afirmando que pessoa nenhuma tem o direito de violar a identidade de uma criança, principalmente porque Bella se sentia uma garota muito feliz com seus cachos, ostentando-os em sua rede social que reunia milhares de seguidores. Os comentários sobre o ato retomam o discurso que toda madrasta é má. O pai, ao se posicionar ao lado da madrasta da garota dizendo que "cabelo cresce", não questiona tal atitude, fazendo-nos lembrar da forma neutra como o pai de Cinderela agia, mesmo vendo a maneira como a nova esposa rejeitava sua filha.

No segundo caso, há uma inversão de papéis, já que desta vez quem se mantém em estado de neutralidade é a madrasta que foi ameaçada pelo marido caso contasse alguma coisa sobre o que aconteceu. Assim, ela prefere preservar sua própria vida, guardando o segredo da morte do enteado. Podemos contrapor essa imagem da madrasta "egoísta" a uma das posições recorrentes sobre a mãe, como aquela que daria a própria vida pelos filhos. Assim, enquanto a mãe se preocuparia com os filhos, a madrasta se preocuparia apenas consigo mesma. Há uma posição de indiferença em relação à criança que não é dela, ou seja, já que a situação não envolve sua cria, tanto faz o que acontecer com a criança, uma vez que a real responsável é a mãe biológica, sendo a madrasta apenas a nova mulher do pai, sem nenhum tipo de interferência afetiva em relação ao filho do marido. $E$ esse afeto que ela não demonstrou condiz com todas as histórias encantadas que envolvem madrastas.

No terceiro caso, a madrasta alega que a morte das crianças teria sido planejada pelo próprio pai, que teria pedido para que ela o ajudasse a matar os filhos dele, e caso não o fizesse, ele mataria o filho dela. Por isso, ela teria ajudado o marido a esquartejar os dois enteados, bem como realizar atos cruéis como colocar um saco plástico na

10Disponível em: <http://g1.globo.com/rs/rio-grande-do-sul/caso-bernardo-boldrini/noticia/2015/04/pai-debernardo-defendeu-madrasta-de-desconfianca-mostram-escutas.html>. Acesso em: 30 nov. 2018. 
GOMES, S.A.; BITENCOURT, D.R.O.

cabeça de um dos garotos ${ }^{11}$. Desse modo, no caso em questão, entra em jogo também a relação mãe e madrasta, havendo uma priorização dos próprios filhos em relação aos enteados, retomando assim um discurso sobre as mães que nunca escolheriam entre dois filhos, mas entre um filho e um enteado o primeiro seria a sua prioridade.

O quarto caso é o conhecido caso da menina Isabela Nardoni, que foi espancada brutalmente pelo pai Alexandre e pela madrasta Ana Carolina Trotta Peixoto Jatobá. Entretanto, investigações atuais apontam que o fato aconteceu "por motivos inexplicáveis, pela madrasta ciumenta de Isabella" e que o pai atuou jogando a menina do sexto andar do prédio. Percival de Souza, repórter policial que escreveu o acontecimento, trata da madrasta como "ciumenta", trazendo, mais uma vez a construção de paráfrase da relação madrasta-enteada, de que toda madrasta é má, invejosa, ciumenta, retomando uma memória que nos permite voltar sempre à representação dessa figura nos contos de fada.

Enfim, o quinto caso trata de um crime também cometido pela madrasta que, segundo o site de notícias, teria dado uma injeção do sedativo midazolan e depois jogado soda cáustica no corpo da criança. Além disso, ainda teria recebido ajuda do pai para enterrar o corpo em uma cova em uma região perto da cidade em que moravam. Em uma conversa telefônica entre Leandro (pai de Bernardo) e sua mãe, a senhora comenta que Gracieli não gostava do garoto. Em outra conversa com a madrinha do garoto, o pai se faz de desentendido e ainda mantém uma frieza ao falar do suposto "sumiço" do menino. Desse modo, mais uma vez é retomada a imagem da madrasta que não gosta dos enteados.

Por fim, faremos a análise de um guia que tematiza as ações da "boadrasta".

\section{Análise do guia: as dez mentiras que as Boadrastas contam}

O manual "As dez mentiras que as boadrastas contam" é de autoria de Bianca Mendonça e foi publicado no blogue "Não é a mamãe". Ao analisarmos o manual podemos, desde o título, perceber que a boadrasta, apesar de boa, é descrita como mentirosa e, além disso, precisa de um manual de instruções para aprender a exercer esse papel. O guia é composto de 10 itens, escritos em primeira pessoa, em que a autora apresenta frases que as boadrastas dizem, mas que, na verdade, como já sugere o título, são mentiras.

${ }^{11}$ Como apresenta o filme brasileiro Tropa de Elite, em que tal ato é utilizado por militares com o intuito de corrigir atitudes ao invés de matar, como ressalta a notícia do site G1. 
GOMES, S.A.; BITENCOURT, D.R.O.

Um exemplo é o terceiro tópico do manual, em que a boadrasta afirma que não fica “imaginando a vida sem ex, enteados, pensão, guarda, audiências, barracos maternos...". Como é uma mentira, devemos interpretar que ela imagina sim como seria a vida sem enteados e, ao afirmar isso, mostra o desejo de que o marido não tivesse filho, ou seja, é como se ela desejasse que os enteados sumissem. Como podemos identificar nas reportagens analisadas anteriormente, em que o enteado se torna uma pedra no meio do caminho da madrasta a ponto de ela queira literalmente sumir com a criança, nesse tópico, esse desejo é retomado apesar de ser uma fala atribuída a uma "boadrasta".

Outra mentira da boadrasta apresentada no quinto item diz respeito ao enteado tirar a sua liberdade de não poder fazer o que tem vontade por causa da criança, bem como andar sem roupa pela casa. Desse modo, o enteado é visto como um estorvo mesmo para a boadrasta, que tem que adotar diferentes hábitos por conta da presença dele.

Por fim, a décima mentira apresentada pelo manual é de que as boadrastas odeiam quando são chamadas de mãe pelos enteados. Assim, como o enunciado deve ser analisado como uma mentira, na verdade, elas adoram quando são chamadas dessa forma, o que aponta para uma concorrência entre o papel da madrasta e o da mãe.

Destarte, apesar de o guia ser direcionado à boadrasta, a análise mostra que as especificações apresentadas retomam uma memória sobre a madrasta como mentirosa, cínica, invejosa, fria, competitiva e falsa. Em todos os itens, ela simula ser boa, mas, na verdade, ou está disputando a posição da mãe ou desejando que o enteado nem sequer exista. Assim, a adição do suposto prefixo "boa" não muda o discurso que circula sobre a madrasta, que é, mais uma vez, repetido. Retomando Courtine (1999), podemos afirmar que do mesmo modo como o chapéu de Clémentis não some da fotografia, apesar da morte de seu dono, o termo "boadrasta" não consegue apagar a marcação negativa dessa figura, uma vez que, ao ser utilizado, a memória retorna. Sendo assim, sob o acontecimento desse novo termo não há, como propôs Pêcheux (2010), a desregulação da memória no sentido de criar uma ruptura, mas há uma restabilização do mesmo discurso.

\section{CONCLUSÃO}

O objetivo deste artigo foi analisar discursivamente o funcionamento do termo "madrasta", incluindo uma análise do termo "boadrasta" que tem circulado como uma 
GOMES, S.A.; BITENCOURT, D.R.O.

alternativa mais suave e afetiva ao primeiro. Para tanto, partiu desde os contos de fadas até os usos atuais do termo em reportagens e no guia.

A análise mostrou que o termo tem circulado com um sentido negativo que é atribuído desde a formação deste, em que a primeira sílaba é interpretada como sendo um prefixo que retoma maldade. Essa interpretação é amparada em diferentes contos de fadas, nos quais a figura da madrasta é descrita como má, invejosa e ciumenta.

A seguir, a análise do termo em reportagens apontou que essa imagem negativa da madrasta tem circulado em notícias que envolvem morte ou algum tipo de crueldade, sendo a madrasta sempre a responsável pelo ato ou por se manter neutra, sem se pronunciar ao presenciar crimes cometidos pelo pai da criança. Por fim, a análise do guia mostrou que, apesar do uso do termo "boadrasta" tentar apagar a imagem negativa dessa figura, essa representação má continua em funcionamento, retomando enunciados da memória discursiva.

Desse modo, o termo "boadrasta" não consegue apagar o sentido negativo dessa figura, pois esta funciona como o avesso da figura da mãe, a qual, por sua vez, é vista, a partir de um viés cristão/católico, como aquela que é "imaculada", possuindo uma carga semântica de veneração, santificada etc. Portanto, o novo termo não tem força discursiva suficiente para apagar a historicidade negativa atribuída à figura.

\section{REFERÊNCIAS}

CARDOSO. E. Cruzamentos lexicais no discurso literário. Estudos linguísticos, São Paulo, v. 39, n.1, mai - ago. 2010. p. 214-222.

CHAMBERLAIN, G. British maternal mortality in the 19th and early 20th centuries. J R Soc Med., v. 99, n.11, p. 559-563, nov. 2006.

COONTZ, S. Marriage, a History: how love conquered marriage. Penguin Books, 2005, Nova York, p. 92.

COURTINE, J. J. O chapéu de Clémentis. Observações sobre a memória e o esquecimento na enunciação do discurso político. Trad. Marne Rodrigues de Rodrigues. In: INDURSKY, F; FERREIRA, M. C. L. (Orgs.). Os múltiplos territórios da análise do discurso. Porto Alegre: Sagra Luzzatto, 1999. p. 15-22.

GRIMM, W. K; GRIMM, J. L. K.Os 77 melhores contos de Grimm. SANDRONI, L. (Org.).Rio de Janeiro: Nova Fronteira, 2018.

HALL, T; WOODWARD, K. Identidade e diferença. Petrópolis, RJ: Vozes, 2000.

HUECK, K. O lado sombrio dos contos de fadas. São Paulo: Abril, 2016. 
$\mathrm{KOCH}$, I; ELIAS, V. M. Ler e compreender: os sentidos do texto. 3.ed. São Paulo: Contexto, 2015.

MENDONÇA, B. S. Manual de instruções: as 10 mentiras que as boadrastas contam. 2015. Disponível em: http://naoeamamae.ne10.uol.com.br/dez-mentiras-queboadrastascontam/\#.XBuFUzB7nIU. Acesso em 30 nov. 2018.

MINUSSI, R. D. NÓBREGA, V. A. A interface sintaxe-pragmática na formação de palavras: avaliando os pontos de acesso da Enciclopédia na arquitetura da gramática.Veredas: Sintaxe das línguas brasileiras, v.1, 2014, p. 161-184.

PÊCHEUX, M. Papel da memória. In: ACHARD, P. et al. Papel da memória. Campinas: Pontes, 2010. p. 49-57.

SILVA, M. E. M. A figura feminina em provérbios brasileiros. Domínios de linguagem. $v$. 8, n. 2, jul/dez, 2014. p. 13 - 24.

\section{Como citar este artigo (ABNT)}

GOMES, S.A.; BITENCOURT, D.R.O. O lado sombrio do termo "MADRASTA": O funcionamento da memória discursiva. SELL, Uberaba, MG, v. X, n. X, p. XXX-XXX, 2019. Disponível em: <inserir link de acesso>. Acesso em: inserir dia, mês e ano de acesso. DOI: inserir link do DOI.

\section{Como citar este artigo (APA)}

Gomes,S.A. \& Bitencourt, D.R.O (2019). O lado sombrio do termo "MADRASTA": O funcionamento da memória discursiva. SELL, X (X), XXX-XXX. Recuperado em: inserir dia, mês e ano de acesso de inserir link de acesso. DOI: inserir link do DOI. 